\title{
Judiciarização das relações sociais e estratégias de reconhecimento: repensando a 'violência conjugal' e a 'violência intrafamiliar'
}

\author{
Theophilos Rifiotis \\ Universidade Federal de Santa Catarina (UFSC)
}

Judiciarização das relações sociais e estratégias de reconhecimento: repensando a 'violência conjugal' e a 'violência intrafamiliar'

Resumo: Trata-se de um ensaio sobre os movimentos sociais que lutam contra a 'violência conjugal' e contra a 'violência intrafamiliar', colocando em debate especialmente a estratégia da chamada 'conquista de ganhos jurídicos'. Aborda-se, inicialmente, a noção de 'violência', problematizando a sua pertinência teórica e seus limites analíticos. Num segundo momento, discute-se a centralidade e/ou exclusividade das medidas no âmbito da judiciarização, especialmente a Delegacia da Mulher, e seus limites e dilemas em termos de lutas por reconhecimento social. A seguir, apresenta-se um esboço da teoria sobre lutas por reconhecimento social fundamentado na obra de Axel Honneth, destacando a base moral das demandas por justiça e a complexidade de sua tradução em termos de direitos. Finalmente, o trabalho aponta para uma leitura crítica da judiciarização das relações sociais, insistindo sobre o caráter tridimensional das lutas por reconhecimento e a pluralidade da agenda política no campo da 'violência conjugal' e 'violência intrafamiliar'.

Palavras-chave: violência, gênero, justiça, família, judiciarização.

\section{Judicialization of Social Relations and Strategies of Recognition: Rethinking 'Conjugal Violence' and 'Intrafamily Violence'}

Abstract: This essay is about social movements that struggle against 'conjugal violence' and 'intrafamily violence', and places in debate the strategy of the so-called 'conquest of judicial gains'. It first approaches the notion of 'violence', questioning its theoretical relevance and its analytical limits. It then discusses the centrality and or exclusivity of the measures in the realm of the courts, particularly the Women's Division and its limits and dilemmas in terms of struggles for social recognition. It then presents a sketch of the theory about struggles for social recognition based on the work of Axel Honneth, highlighting the moral base of demands for justice and the complexity of their translation in terms of rights. In conclusion, the study points to a critical reading of judicialization of social relations, insisting on the tridimensional character of the struggles for recognition and the plurality of the political agenda in the field of 'conjugal violence' and 'intrafamily violence'.

Key words: violence, gender, justice, family, judicialization. 


\section{Apresentação}

O presente texto é resultante dos debates realizados no Grupo de Trabalho Violência e justiça: questões teóricas e etnográficas em gênero e família da VII Reunião de Antropologia do Mercosul (Porto Alegre, 2007) e tem como objetivo apresentar um conjunto de reflexões sobre as estratégias políticas de luta contra a 'violência conjugal' e a 'violência intrafamiliar', mas principalmente da primeira, com ênfase na sua tradução judiciarizante ${ }^{1}$. Ele apresenta um desenvolvimento de idéias que vêm sendo debatidas desde 2002, no marco da XXIII Reunião Brasileira de Antropologia (Gramado), seguindo-se da V Reunião de Antropologia do Mercosul (Florianópolis, 2003) e da VI Reunião de Antropologia do Mercosul (Montevidéu, 2005), onde foram objeto de reflexão inúmeras pesquisas sobre os modelos de sociabilidade, identificados como 'violentos', e sobre os dispositivos sociais de acesso à justiça, com ênfase nos campos do gênero e da família. Esses debates trouxeram importantes contribuições teóricas e etnográficas que, além de propiciarem um rico intercâmbio internacional, revelaram-se promissoras, sobretudo por tratarem de um campo de pesquisa eivado de impasses e dilemas teóricos, éticos e políticos, exigindo um esforço reflexivo contínuo sobre a produção acadêmica e sobre as práticas de intervenção social. Assim, apresento aqui um texto, que é, antes de mais nada, um resultado dos debates e das contribuições de todos os participantes daqueles eventos, onde enfoco questões relativas a um campo que vem merecendo cada vez maior destaque na literatura especializada, ao qual tenho chamado de judiciarização das relações sociais, objeto central deste ensaio.

A judiciarização das relações sociais é um campo, ou melhor, uma abordagem que apesar de recorrente em muitos dos trabalhos sobre 'violência conjugal', 'violência de gênero', 'violência intrafamiliar' etc. é ainda muito pouco explorada e sobre a qual me tenho dedicado nos últimos anos (RIFIOTIS, 2003, 2006a, 2007a, 2007b). Recente e controversa tal abordagem será objeto deste trabalho, e será aqui enfocada especialmente a partir das estratégias de luta contra a 'violência conjugal'. Concretamente, tratarei de apresentar um roteiro de questões para a análise dos mecanismos de produção da judiciarização nas relações conjugais e intrafamiliares no Brasil².

\section{Da violência ao direito}

Iniciamos a parte substantiva deste ensaio com uma discussão sobre os discursos contemporâneos vinculados à 'violência'. Coerentemente com a postura crítica que venho adotando neste campo, reto- mo em linhas gerais os trabalhos publicados anteriormente (RIFIOTIS, 1997, 1999 e 2006b). Na perspectiva genealógica que adoto, a 'violência' é um problema social e não um objeto analítico. De fato, 'violência' é um termo que funciona nos discursos como um operador que, ao mesmo tempo, descreve e qualifica eventos:

\begin{abstract}
'Violência' é uma palavra singular. Seu uso recorrente a tornou de tal modo familiar que parece desnecessário defini-la. Ela foi transformada numa espécie de significante vazio, um artefato sempre disponível para acolher novos significados e situações. O seu campo semântico tem uma regra de formação: a constante expansão. A aparente unidade deste termo resulta de uma generalização implícita dos diversos fenômenos que ela designa sempre de modo homogeneizador e negativo (RIFIOTIS, 1999, p. 28).
\end{abstract}

Entendo, portanto, que nos trabalhos de pesquisa neste campo é oportuna e mesmo necessária a leitura crítica do lugar de onde estamos construindo os nossos discursos sobre a 'violência'. Afinal, a partir de qual sensibilidade historicamente construída percebemos distintos fenômenos sob aquela forma singular, negativa e homogeneizada? Ou ainda mais radicalmente, qual é o lugar da indignação e do compromisso ético que nos leva a postular no campo problemático das violências uma oposição dicotômica e redutora em termos do par 'vítima/agressor', por vezes tomado como homólogo de vítima/acusado, própria do jurídico? A nossa fala está focada nas vítimas e no seu sofrimento, de tal modo que descrevemos/qualificamos atos associados a elas como "violentos', condenando e entendendo-os como anti-sociais, a partir da imperativa empatia com as 'vítimas'. É por esta razão que tenho insistido em marcar a indignação e a exclusividade dessa leitura em um lugar eminentemente moral da crítica social, com um discurso social crítico sem ser analítico ${ }^{3}$. Trata-se, sem dúvida, de uma dimensão com desdobramentos éticos e teóricos que apenas estão começando a ser delineados no horizonte dos nossos estudos. Porém, já é possível afirmar que devemos problematizar a retórica da denúncia quando ela implica na redução da complexidade e da diversidade dos próprios fenômenos denunciados, e, sobretudo, no limite, quando ela é colocada como um lugar de discurso político auto-suficiente e autoconfirmador ${ }^{4}$.

A primeira conseqüência da reflexão crítica sobre o campo da 'violência', aplicada às discussões sobre gênero e família, seria então nos perguntarmos sobre os limites e efeitos produzidos por noções recorrentes nos nossos trabalhos em 'violência intrafamiliar' e 'violência conjugal' ou 'violência de gênero'. Pode-se considerar, por exemplo, que a expressão 'violência conjugal' tem na sua composição 
uma categoria descritivo-qualificadora; 'violência', é um substantivo que tem uma função qualificadora e que passa nessa expressão por uma operação lingüística deixando de ser uma qualificação, para tornar-se - no mesmo movimento - uma realidade substantiva. Tal operação discursiva instaura para o pensamento uma nova realidade que passa a ser descrita e qualificada como 'violência conjugal'. Tal processo pode ser estendido a um vasto conjunto de expressões em curso que operam justamente a substantivação da 'violência'.

Evidentemente, a criação de tais categorias é fundamental no jogo das estratégias políticas, e não é nosso objetivo aqui questionar estratégias políticas, mas tão somente contribuir para a sua reflexão crítica. No caso da 'violência conjugal' ou 'violência de gênero', sem discutir aqui as diferenças entre elas ${ }^{5}$, parece que ambas operam segundo o mesmo princípio. A dimensão política neste caso é explícita e desejada pelos movimentos feministas, estando na base da própria afirmação do caráter político das relações de gênero. Correndo o risco de simplificar excessivamente a questão, para bem definir o aspecto aqui delineado, perguntaria se a centralidade da noção de 'violência conjugal' não se teria tornado uma espécie de operador simbólico de catálise das formas assimétricas, hierárquicas e excludentes da desigualdade de gênero? Afinal, ao longo dos anos 1980, a 'violência conjugal' tornou-se uma espécie de ícone das lutas feministas. De fato, "[...] os movimentos sociais que lutam contra a impunidade nos casos de 'violência de gênero' são, ao mesmo tempo, movimentos locais e globais, cuja dimensão transversal representa um desafio maior e coloca a necessidade de pesquisas comparativas entre "soluções locais", (RIFIOTIS, 2004, p. 85). Enfatizo aqui, tratar-se de uma categoria internacionalizada (SIMIÃO, 2005), que tomou formas locais, é verdade, mas que geralmente - apesar das especificidades históricas e sociais -, caracteriza-se fundamentalmente por apelar a serviços de polícia e de um modo geral ao sistema judiciário (RIFIOTIS, 2003, 2004). Nos últimos anos, outras estratégias ganharam mais espaço, como referido mais adiante, sem que a categoria 'violência conjugal' deixasse de ser um importante operador simbólico para garantir e ampliar o acesso ao sistema de justiça e reduzir a impunidade nos casos de "violência contra as mulheres'. A prevalência de 'soluções locais' articuladas a mecanismos jurídicos contribuiu para ampliação das áreas de litígio alcançadas pelo sistema judiciário e, ao mesmo tempo, para a desvalorização de outras formas de resolução de conflitos. Tal processo se estende para além deste campo específico e toma uma forma geral que chamamos de 'judiciarização das relações sociais' (RIFIOTIS, 2003, 2004, 2006a, 2007a, 2007b) ${ }^{6}$. Em geral, ela se expressa pela criminalização secundária, ou seja, sem um tipo penal específico ${ }^{7}$, e são desenvolvidas políticas específicas para os serviços de polícia, ou adaptações de mecanismos jurídicos. No Brasil, foi típica deste processo a criação, a partir de 1985, de uma organização da polícia judiciária chamada Delegacia Especial de Proteção à Mulher, ou simplesmente Delegacia da Mulher (DM).

Estamos frente a uma expressão 'local' de um amplo e diversificado quadro de experiências sociais com caráter judiciarizante ${ }^{8}$. Assim, a Delegacia da Mulher (DM) deve ser pensada como estratégia de 'empoderamento', ou seja, de facilitar mecanismos que aumentam o acesso a recursos e a oportunidades para a ação pró-ativa de pessoas e grupos minoritários, seja pelo ganho de poder, legitimidade, autonomia, capacidade de ação pessoal e coletiva (RAPPAPPORT, 1987 apud DAMANT; BELANGER; PAQUET, 2000, p. 79-80). Foi exatamente sob este prisma que realizei uma pesquisa etnográfica sobre as práticas polícias no quotidiano da DM através da qual pude constatar que, via de regra, o tratamento dado às queixas não segue a tramitação típica do inquérito policial, requerida por uma instituição de polícia judiciária como é a DM. De fato, como observado no trabalho de campo, as policiais que atuam nas Delegacias da Mulher entendem que estão 'enxugando gelo', dadas a repetição de casos e a falta de encaminhamento processual. Enquanto que as mulheres que utilizam os serviços não parecem entender positivamente a instauração do inquérito policial, seja porque elas mesmas em geral retiram a queixa, seja porque não desejam tal procedimento. Na realidade, pelo que se pôde observar, a instituição cumpre um importante papel de acolha e processamento, servindo de apoio para as mulheres vitimadas. Assim, pode-se afirmar que os serviços de polícia são ressignificados. Fundamentalmente, observei um uso da queixa (Boletim de Ocorrência) como mecanismo de ameaça e renegociação de pactos conjugais; e da intimação, por sua vez, apropriada como mecanismo para criar o 'diálogo' e o reconhecimento da 'culpa', dar o 'susto' e colocar o companheiro no 'bom caminho'. Em síntese, a DM seria um espaço de recepção, acolha de queixas, de exercício de controvérsia apoiado na figura da autoridade policial (RIFIOTIS, 2003, 2004). Tais resultados são referendados por outros trabalhos desenvolvidos nos últimos anos sobre a Delegacia da Mulher em diferentes contextos no Brasil (MUNIZ, 1986; SOARES, 1999; RIFIOTIS, 2000; RIFIOTIS; SANTOS, 2002, 2005; DEBERT, 2002).

Com a criação da Lei 9099 em 1995 (BRASIL, 2008), as causas relativas a penas menores de dois anos foram deslocadas para os Juizados Especiais Criminais (JECRIM). A partir dessa lei, grande parte das causas recebidas na DM passa a ter um encaminhamento específico: um acordo no tribunal especial, visando 
maior 'celeridade processual'. Segundo Oliveira (2006), em estudo etnográfico sobre o JECRIM em Campinas, a informalidade e a economia processual, que eram objetivos daqueles juizados visando ampliar o acesso aos serviços de justiça, no caso da 'violência de gênero', podem ter gerado a sua despolitização, invisibilização e até mesmo a sua reprivatização $0^{9}$. acordo a que são submetidas as partes corresponde a uma forma de contornar o enfrentamento do conflito, através de uma 'compensação', geralmente realizada em termos do que considero o ícone daqueles tribunais: a 'cesta básica'.

No âmbito da nossa reflexão sobre a judiciarização, importa destacar que se trata de uma passagem de uma leitura centrada na 'violência' para outra focada no direito. Neste processo, sendo a DM um serviço de polícia judiciária, uma correia de transmissão entre a identificação, o processamento de práticas criminais e o poder judiciário, é fundamental refletirmos sobre o descompasso entre os objetivos institucionais e a estratégia política subjacente. $\mathrm{Na}$ realidade, o trabalho de campo permitiu a identificação de um duplo descompasso. Um primeiro, reside na diferença entre a perspectiva que fundamenta a criação das Delegacias da Mulher, visando a luta contra a impunidade nos casos de "violência de gênero', e as práticas policiais concretas na DM. Com efeito, o seu papel de investigação e produção de provas em muitos casos torna-se secundário, em relação a serviços de orientação sobre direitos, assistência social e apoio psicológico

(RIFIOTIS; SANTOS, 2005). Um segundo descompasso, diretamente ligado ao anterior, é atinente à apropriação que as mulheres vitimadas fazem concretamente daquelas instituições, e que foi identificado por Muniz (1996) em termos da diferença entre 'fazer justiça', demanda e expectativa daquelas mulheres, e 'entrar na justiça', este último sendo visto de modo negativo e não equivalente ao primeiro. Muito embora a resposta judiciarizante da DM não corresponda na grande maioria dos casos às demandas e expectativas, as Delegacias da Mulher desenvolveram, conforme as especificidades locais, uma série de serviços e estratégias de atendimento que as torna um importante recurso coletivo.

A DM e o JECRIM como mecanismos judiciarizantes não parecem produzir os efeitos tipicamente esperados em termos de empoderamento nas situações de 'violência conjugal' e 'violência intrafamiliar'. Trata-se de uma questão ainda não suficientemente estudada e que permitiria inclusive uma melhor com- preensão do contexto em que se deu a aprovação da Lei 11.340 (BRASIL, 2007), conhecida como Lei Maria da Penha, que no seu artigo $1^{\circ}$. traz a seguinte auto-definição: "Esta Lei cria mecanismo para coibir e prevenir a violência doméstica e familiar contra a mulher." Tipifica no seu artigo $5^{\circ}$. de modo bastante abrangente a noção de "violência doméstica e familiar contra a mulher" como "qualquer ação ou omissão baseada no gênero que lhe cause morte, lesão, sofrimento físico, sexual ou psicológico e dano moral ou patrimonial." Passamos então, a partir de 2006, a uma criminalização primária da 'violência de gênero' no Brasil, correspondendo localmente a convenções internacionais, e a um entendimento da necessidade da via penal, que não é uma tendência hegemônica na matéria como veremos a seguir.

Foge do escopo do presente texto examinar os movimentos sociais que se organizam em torno dos direitos das mulheres e que atuaram mais diretamente na 'violência de gênero' e os debates internos a esses movimentos. Porém, o quadro desenhando do ponto de vista da judiciarização estaria incompleto se não fossem mencionadas as iniciativas de mediação e os trabalhos com os 'agressores' que também correspondem a estratégias políticas naquele campo. Além do mais, importantes trabalhos na área já apontavam os limites da via exclusivamente judiciarizada, sobretudo aqueles que destacam a caracterização relacional da 'violência de gênero', negando a prevalência da leitura dicotômica e polar: vítima/ agressor (GREGORI, 1993; GROSSI, 1995). Os estudos e trabalhos de intervenção de Welzer-Lang (1991) com 'homens violentos' mostram como esta categoria é inadequada para dar conta da 'violência de gênero', e que é a indignação que nos leva a considerá-los estrangeiros das relações entre gêneros. Aliás, a própria construção do masculino nestes termos, como afirmou Welzer-Lang (2004, s.p., grifo nosso), é problemática:

\section{Aujourd'hui, il existe toute une remise en cause du masculin sans qu'il y ait cependant en face ni analyse ni modèle pour voir réelment se dessiner des modèles alternatifs masculins. Les estudes de genre concernent encore principalment les femmes. 'Les hommes apparaissent alor comme un groupe naturalisé'.}

Em resumo, é possível identificar um quadro com duas frentes de leitura da 'violência de gênero', as quais não precisariam ser excludentes, mas que a 
Lei 11.340/06, sobretudo, se a prática jurídica tornar preponderante o caráter penal de ação pública incondicionada, pode separar radicalmente. De um lado teríamos uma tendência, digamos, relacional, voltada ao trabalho com os agressores, a mediação, a busca de soluções extra-judiciais etc. De outro, uma ênfase na dimensão penal, da responsabilização legal. A tensionalidade entre essas duas frentes de leitura, no meu entendimento, não deve ser considerada por si mesma negativa. Afinal, ela pode ser um elemento positivo para a geração de uma pluralidade de intervenções sociais, que contribuiriam para a ampliação, multiplicação e diversificação de oferta de serviços públicos e iniciativas de grupos organizados. Assim, poder-se-ia ampliar também o acesso à justiça, o que possibilitaria a conexão entre outros serviços sociais, garantindo o desenvolvimento da cidadania. Trata-se de uma questão que mereceria ser objeto de análise desde o início da implantação concreta da Lei 11.340. Nos limites deste trabalho quer-se colocar em debate tais disputas, pontuando seus dilemas e limites. Por esta razão, iniciei esta apresentação fazendo um percurso pelo espaço conceitual da 'violência' e seus rebatimentos no campo do direito. Retomemos agora o debate a partir de outro prisma, o da justiça, ou melhor, do direito ${ }^{10}$.

\section{Do direito ao reconhecimento}

Na continuidade do texto serão discutidas as questões relativas à 'violência conjugal' a partir das demandas sociais que originaram a DM enfocando a sua relação com o direito. Como sabemos, o direito ocupa hoje no Brasil uma centralidade nas discussões políticas e por esta razão são fundamentais os trabalhos que problematizam o seu lugar nas estratégias dos movimentos sociais, especialmente no campo da 'violência' como no caso da criminalização da 'violência conjugal'. É preciso conhecer melhor o lugar do legislativo, criador de leis, e o do exercício concreto destas pelo sistema judiciário que cria elementos normativos que contribuem para a definição, manutenção e mesmo mudança de relações sociais, possibilitando a configuração de novos sujeitos sociais (RIFIOTIS, 2007b).

Sendo o direito um importante elemento simbólico da construção da legitimidade, devemos refletir sobre o seu lugar como parte da estratégia de visibilização e reconhecimento das lutas sociais no campo do gênero. Para tanto, sigo a linha de argumentação que vem sendo desenvolvida aqui, ou seja, apresentar uma análise crítica da judiciarização das relações sociais destacando agora um duplo aspecto: a expansão do judiciário e as estratégias de reconhecimento focadas no judiciário. Começo discutindo um conjunto de proposições sobre o direito, envolvendo questões sobre legitimidade, expansão do judiciário e a criminalização primária da 'violência conjugal', e num segundo momento, será objeto de reflexão a contribuição da teoria de Axel Honneth sobre as lutas sobre reconhecimento (HONNETH, 2003).

Em primeiro lugar, tratando-se da legitimidade e do direito, cabe lembrar uma vez mais, seguindo Weber (1995a, p. 65), que a forma de legitimidade mais importante na sociedade moderna é a crença na legalidade. Em outros termos, a dimensão jurídica é sem dúvida fundamental na construção da legitimidade. Porém, como o próprio Weber (1995b, p. 73) lembra a ordem respeitada unicamente pela racionalidade quanto a fins é geralmente menos estável do que aquela baseada no 'costume', que se afirma pelo seu caráter rotineiro e graças à sua exemplaridade ${ }^{11}$. Neste sentido, uma primeira conseqüência seria considerar a estratégia judiciarizante como uma espécie de medida de curto prazo em termos dos desdobramentos desejados na modulação das relações de gênero na nossa sociedade.

Devemos também considerar outro aspecto importante da judiciarização que é a existência de dois grandes movimentos, ambos internacionais e com desdobramentos locais específicos que se cruzam continuamente: um no campo do feminismo e outro no jurídico. O primeiro questiona as diferenças sociais e busca a conquista da igualdade e da afirmação do direito à diferença, colocando-se numa luta por reconhecimento social da desigualdade de gênero. Ele tem no reconhecimento da 'violência de gênero', pela via judiciária, uma importante estratégia política. Tal movimento não pode ser visto isoladamente daqueles que têm lugar no âmbito do próprio judiciário, notadamente os movimentos alternativos ao direito tradicional, cujo horizonte é a desregulação da vida social, a desjudiciarização, tipicamente reconhecível no Brasil através do mecanismo da mediação. $\mathrm{O}$ segundo movimento, associado a contextos neoliberais e de Estado mínimo, como vivemos nos últimos anos, também corresponde a uma estratégia para fazer face à crescente demanda e ao excesso de formalismo, altos custos, morosidade etc. Há ainda que considerar que os referidos movimentos no Direito não são lineares e tampouco unívocos. Concretamente, no direito há outra uma vertente de ampliação da criminalização dos 'problemas sociais'. Neste quadro ambivalente, que foi detalhadamente descrito em Pedroso, Trincão e Dias (2001), e numa publicação decorrente desta de Pedroso (2002), emerge a questão de um paralelismo entre demandas dos movimentos feministas e disputas internas do campo jurídico, reforçando-se ou excluindo-se mutuamente, conforme seja adotada uma perspectiva judiciarizante ou desjudiciarizante. Explico melhor este ponto porque ele atua em dois planos distintos que são as dinâmicas do judiciário e as dos movimentos sociais e 
pode se prestar a mal-entendidos: ao reforçarmos a tendência da criminalização penal da 'violência conjugal', aderimos aos discursos que convergem em defesa da expansão penal; ou ao apoiarmos medidas de mediação e trabalhos com 'agressores' etc., atuamos junto ao movimento de informalização. Tratase de um movimento que implica numa captura de um plano pelo outro. Deste modo, a criminalização como reconhecimento pelo Estado - via sistema penal - poderia ser considerada como uma 'dádiva ambivalente', no sentido dado por Butler na sua discussão sobre o reconhecimento do 'casamento gay"12, pois a criminalização da 'violência conjugal' exige a aceitação do tratamento penal dos casos. O que concretamente implica na polaridade vítima-acusado, sendo que a vítima torna-se testemunha do seu próprio caso no processo. Neste contexto processual, os autos reproduzem um universo limitado das experiências sociais, criando seus próprios mundos aceitáveis e, como afirmou Corrêa (1983), produzem uma fábula em torno da qual se organizam os personagens e eventos que são colocados na cena dos processos penais. $\mathrm{O}$ processo penal domestica por assim dizer a conflitualidade, organizando-a numa polaridade excludente, típica do princípio do contraditório no processo penal, traduzindo em categorias jurídicas polares a complexidade das relações de gênero.

As perspectivas feministas e jurídicas, portanto, cruzam-se num quadro complexo de disputas políticas. Por exemplo, para algumas tendências do movimento feminista é questionável a mediação, pois ao invés de eqüidade, igualdade e protagonismo dos sujeitos, pode ocorrer uma revitimização e reprivatização da 'violência de gênero' (DIGNEFFE; PARENT, 1998). Critica-se a mediação por reproduzir a condição de desigualdade, mas a intervenção penal do Estado priva a vítima de seu espaço e anula o exercício do seu poder de decisão. Aliás, para algumas correntes feministas, a intervenção penal com seu caráter compulsório e automático seria um grande obstáculo no campo da "violência de gênero'(PARENT, 2002, p. 101).

A universalização dos mecanismos penais é altamente problemática no âmbito das 'violências' conjugal, de gênero e intrafamiliar ${ }^{13}$. Como mostrou a clássica 'experiência de Mineápolis' de 'acusação automática' de agressores, os efeitos produzidos pela intervenção policial são muito diferentes e contingentes, podendo, inclusive, redundar em aumento da 'violência de gênero’ (SHERMAN, 1992). A dimensão transversal dos fenômenos reunidos sob a designação de 'violência de gênero' (tempo, espaço, classe social etc.) permanece como um desafio maior e faz apelo aos estudos comparativos tanto em termos de vitimização, que permitiria, inclusive, discutir a pressuposta universalidade das experiências e das percepções, quanto de práticas e soluções locais ${ }^{14}$.
Pelo que foi apresentado até aqui, parece que fica caracterizado que o jurídico é ao mesmo tempo uma solução e um problema, uma 'solução-problema'. Ele não deve ser considerado um fim em si mesmo e tampouco os objetivos sociais projetados sobre ele se realizam automaticamente, devendo ser objeto de monitoramente contínuo, como condição necessária para a sua efetividade. Entendendo que os 'ganhos jurídicos' - e num plano mais geral as lutas por justiça - são reivindicações sociais por reconhecimento legal, leia-se legitimidade, perguntamo-nos até aqui sobre o seu significado e limites. Cabe agora colocar outra questão: o que entendemos por reconhecimento e como ele opera? Para responder a tal questionamento, recorremos aos fundamentos da teoria do reconhecimento sistematizados por Honneth (2003), que serviu de inspiração para o presente trabalho.

Luta por reconhecimento. A gramática moral dos conflitos sociais de Axel Honneth (2003) é uma obra de referência para a análise da temática do reconhecimento e das lutas sociais contemporâneas. Seu maior mérito está em situar a questão do reconhecimento e das reivindicações políticas relativas à diferença em termos dos fundamentos da interação social, ou seja, a base das nossas relações com o outro $^{15}$. Para as necessidades da exposição, apresento alguns aspectos da teoria de Honneth, começando por lembrar que ele adota uma abordagem social subjetiva, o que permite situar o reconhecimento em termos das experiências da alteridade. Ao situar a sua abordagem naquela perspectiva, ele pode trabalhar as possibilidades de auto-realização dos sujeitos sociais em três formas de reconhecimento: amor, direito e solidariedade. Sendo que elas: "[...] formam dispositivos de proteção intersubjetivos que asseguram as condições de liberdade externa e interna, das quais depende o processo de uma articulação e de uma realização espontânea de metas individuais de vida" (HONNETH, 2003, p. 274).

No sentido da auto-realização pessoal, haveria três esferas em que se pode dar o reconhecimento: pelo outro próximo (amor, amizade), pelo direito (direito à igualdade, direito à diferença), e solidariedade (dignidade). Em outros termos, as lutas por reconhecimento envolveriam respectivamente a confiança em si mesmo (identidade pessoal e autonomia), o respeito por si (direitos iguais) e a estima por si (sentir-se considerado e contribuindo com a sua coletividade). Para Honneth, há um último aspecto relevante para o debate sobre as lutas por reconhecimento: essas seriam melhor compreendidas se for colocado em primeiro plano a idéia de os conflitos serem sempre motivados por convicções morais, ainda que em diferentes graus. Assim, define-se na teoria de Honneth o lugar central que ocupa a moral nos conflitos e nas lutas por reconhecimento. Finalmente, esperando ter mostrado a potencialidade e a pertinência desta abordagem para 
a temática específica do presente ensaio, volto a lembrar que foge totalmente das pretensões do presente texto fazer uma exposição da obra de Honneth e remeto os interessados ao texto integral.

No campo específico em que estou situando o debate, cabe assinalar desde logo que o cruzamento entre as estratégias dos movimentos feministas e o campo do reconhecimento não foi realizado pelo próprio Honneth. Aliás, ele afirma explicitamente que, apesar dos trabalhos de filosofia política no campo do feminismo freqüentemente cruzarem as teorias do reconhecimento, ele não tratará diretamente da questão (HONNETH, 2003, p. 25). Portanto, ao evocar a teoria do reconhecimento, estou apenas a propor um campo de investigação, ou melhor, a justificar a sua pertinência, levantando pontos para o debate, sem pretensão de dar-lhes uma contribuição concreta, para passar agora a uma articulação mais substancial com o objeto do ensaio.

Um primeiro ponto que quero destacar está ligado à presença de dois tipos de demandas por justiça social: redistribuição e política de reconhecimento. A separação entre estas duas esferas, ainda que questionável pela dualidade mostra-se interessante para que não sejam negligenciadas as reivindicações mais tipicamente 'econômicas' ${ }^{16}$. Neste ponto, compartilhamos da perspectiva de Honneth (2003, p. 261) que considera a luta por reconhecimento como uma gramática geral dos conflitos sociais, que não implica na criação de um modelo que substitua ou dê preferência a uma ou outra dimensão, "[...] pois permanece sempre uma questão empírica saber até que ponto um conflito social segue a lógica da persecução de interesses ou a lógica da formação da reação moral.”. Neste sentido, é importante considerar que os movimentos sociais que reivindicam direitos têm como objetivo respeito e reconhecimento. Seguindo o historiador inglês E.P.Thompson e inspirado pelos trabalhos de B.Moore, Honneth sustenta a tese de que os conflitos sociais nunca são uma exteriorização da miséria e da privação econômica, mas o resultado de uma métrica de expectativas morais colocada para a sociedade. Tal perspectiva é fundamental na sua tese de que os confrontos sociais ocorrem segundo um padrão de uma luta por reconhecimento, o que está sintetizado na seguinte passagem:
[...] os sentimentos de injustiça e as experiências de desrespeito, pelos quais pode começar a explicação das lutas sociais, já não entram mais no campo de visão somente como motivos da ação, mas também são estudados com vista ao papel moral que lhe deve competir em cada caso no desdobramento das relações de reconhecimento (HONNETH, 2003, p. 265).

Para situar mais diretamente a relação entre a temática da juridiciarização e as estratégias por reconhecimento, apresento abaixo o quadro1 onde se verificam as três formas de reconhecimento e as correspondentes formas de desrespeito.

Procurando seguir o pensamento de Honneth, numa primeira aproximação com o campo das 'violências' no âmbito do gênero e da família, em grandes linhas, estaríamos frente a um quadro de quebra de reconhecimento de 'relações primárias' marcado por maus-tratos e violação. O reconhecimento seria procurado numa mudança, digamos, interior, que poderia ter desmembramentos nas relações jurídicas (direitos) e na construção de uma comunidade de valores de respeito mútuo ${ }^{17}$. Ora, como sabemos pelo estudo etnográfico, a passagem da esfera da 'intimidade' para a das relações jurídicas não se faz sem problemas, e o modelo de Honneth fornece uma pista interessante para pensarmos tal passagem. Pelo que foi exposto da teoria do reconhecimento, desprende-se que aquela passagem se dá numa área de tensão entre uma forma de desrespeito (maus-tratos, violação) e outra forma de reconhecimento que são as relações jurídicas. Tal tensão analiticamente pensada corresponde aos descompassos identificados anteriormente entre as expectativas dos movimentos feministas, quanto às mulheres vitimadas e aos serviços judiciários oferecidos no quadro da judiciarização. Trata-se de pensar algo mais do que uma simples oposição entre as esferas da intimidade e do direito, do privado e do público. Na abordagem aqui adotada, não há fronteiras fixas e impenetráveis, pois o reconhecimento pelo direito penetra a esfera da intimidade, e as relações jurídicas atuam como referência à formação de comunidade de valores (HONNETH, 2003, p. 278).

\section{Quadro 1 - Formas de reconhecimento e formas de desrespeito de Honneth}

\begin{tabular}{llll}
\hline $\begin{array}{l}\text { Formas de } \\
\text { reconhecimento }\end{array}$ & $\begin{array}{l}\text { Relações primárias } \\
\text { (amor, amizade) }\end{array}$ & $\begin{array}{l}\text { Relações jurídicas } \\
\text { (direitos) }\end{array}$ & $\begin{array}{l}\text { Comunidade devalores } \\
\text { (solidariedade) }\end{array}$ \\
Formas de desrespeito & $\begin{array}{l}\text { Maus-tratos e } \\
\text { violação }\end{array}$ & $\begin{array}{l}\text { Privação de direitos } \\
\text { e exclusão }\end{array}$ & $\begin{array}{l}\text { Degradação e } \\
\text { ofensa }\end{array}$ \\
\hline
\end{tabular}

Quadro reproduzido parcialmente de Honneth (2003, p. 211). 
A teoria do reconhecimento, portanto, auxilia-nos no sentido de pensarmos o lugar que ocupa a judiciarização como estratégia política. A judiciarização atua nas relações jurídicas, situada entre as esferas da intimidade e da coletividade de valores, mostrando, assim, seus limites claramente e exigindo também estratégias específicas de atuação nas outras duas esferas. Além do mais, o Estado, o aparato judiciário, as práticas quotidianas dos operadores do direito, tendem a se autonomizarem e não atenderem as demandas sociais que guiaram a sua criação, principalmente na legislação penal. Portanto, creio que a questão chave aqui para a discussão da judiciarização poderia ser uma leitura crítica do significado das estratégias políticas que são focadas principalmente nos direitos e na multiplicação de 'ganhos jurídicos'. Afinal, estes últimos parecem estar se transformando em uma espécie de moeda de troca, um equivalente geral marcado por um fundamentalismo jurídico e no limite de uma espécie de populismo penal, com conseqüências para as expectativas dos movimentos sociais e o exercício concreto da democracia. Como afirmamos num trabalho anterior:

De hecho, existe el riesgo de que los textos legislativos se autonomicen en la práctica jurídica y no atiendan las demandas sociales que han guiado su concepción, principalmente en el ámbito de la legislación penal. Por eso es preciso discutir la efectividad de las garantías para el acceso a la justicia, así como el desarrollo de sujetos de derecho. Sólo así se asegura el carácter democrático de de la creación de políticas sociales (RIFIOTIS, 2007a, p. 243).

\section{Considerações finais}

Retomando o ponto inicial, quero reafirmar que a sistematização do debate teórico sobre a judiciarização das relações sociais ainda está em fase de elaboração e que o conjunto de questões abarcadas excede em muito os conhecimentos aqui levantados. Porém, acreditando que o seu debate é importante e urgente, ousei apresentar neste texto as minhas observações preliminares. Entendo que assim estarei contribuindo para o questionamento da judiciarização no âmbito da 'violência conjugal' e 'violência intrafamiliar', não por uma questão abstrata e de princípio geral, mas pela sua cen- tralidade na agenda política atual. Questionando a centralidade e, sobretudo, a exclusividade das lutas por direitos, procurei também apontar a necessidade de apoio político para as lutas por reconhecimento em todas as esferas da vida social.

Certamente, a atuação política no campo do reconhecimento jurídico é fundamental e intrínseca aos jogos políticos nas sociedades democráticas e sua presença se estende a todas as esferas sociais, porém a sua centralidade deve ser objeto de uma reflexão crítica. Assim, ao evocar a teoria do reconhecimento social de Honneth (2003, p. 265) espero ter colaborado para mostrar que:

[...] os sentimentos de injustiça e as experiências de desrespeito, pelos quais pode começar a explicação das lutas sociais, já não entram mais no campo de visão somente como motivos da ação, mas também são estudados com vista ao papel moral que lhe deve competir em cada caso no desdobramento das relações de reconhecimento.

Ou seja, os sentimentos morais são o húmus que pode favorecer ou não as lutas por reconhecimento, e seu estudo é uma peça fundamental nessas lutas. $\mathrm{O}$ que remete o estudioso a refletir sobre a pluralidade da agenda política e a fazer a leitura atenta dos aspectos da moralidade que lhe permitam uma análise acurada dos contextos específicos e dos significados locais em que são evocados os temas da 'justiça' e da 'injustiça', e em que contextos eles se tornam mobilizadores para os sujeitos sociais. Afinal, a judiciarização das relações sociais não é um equivalente de acesso à justiça, democratização e cidadania. Pois, ainda que faça parte da dinâmica das sociedades democráticas, tal processo pode, inclusive, limitar ou ameaçar a cidadania e a democracia, transferindo e canalizando no e para o Estado as lutas sociais ${ }^{18}$.

Num plano mais geral, caberia aproximar este debate daquele levantado por Scott (2005), ao discutir a tensão entre diferença e igualdade, pois compartilhamos de suas idéias quando argumenta que entre esses dois pontos não há solução simples ou interesse em manter oposições. São tensões que têm sua solução contingente, e não escolhas morais ou éticas absolutas: "Pelo contrário, reconhecer e manter uma tensão necessária entre igualdade e diferença, entre direitos individuais e identidades grupais, é o que possibilita 
encontrarmos resultados melhores e mais democráticos" (SCOTT, 2005, p. 12).

Finalmente, gostaria de lembrar que o direito, apesar de sua importância capital na vida social democrática e sua transversalidade nas distintas esferas sociais, opera de um modo específico que deve ser objeto de reflexão no debate aqui proposto. Refirome ao fato do direito operar pela tradução de conflitos através de um equivalente geral (um tipo penal, por exemplo) e a partir dele definir uma modalidade de prova ou enfrentamento legal a ser seguida. Num estudo intitulado L'amour et la justice comme competénces. Trois essais de sociologie de l'action, Boltanski (1990) propõe uma reflexão sobre a justiça na qual ganha relevo esta questão. Para ele, a existência de vários princípios de equivalência legítimos, possibilita um permanente relançar do litígio tomando em seu favor um novo equivalente, o que nos remete a pensar nos limites da justiça, entendida como direito, e na busca de outros horizontes para além do direito: "[La justice] peut, au moins un temps, canaliser la dispute en la soumettant à son ordre. Elle est impuissante à l'arrêter. Pour arrêter la dispute en justice, il faut donc toujours aller chercher autre chose que la justice" (BOLTANSKI, 1990, p. 140).

Porém, devemos ter claro que a prática do direito é também um lugar de luta e não apenas a última e objetiva palavra sobre o conflito, a questão estará sempre mais além das observações teóricas que possamos levantar. Sabemos que os “[...] os sujeitos precisam encontrar reconhecimento numa sociedade moderna como seres tanto autônomos quanto individualizados" (HONNETH, 2003, p. 269). Todavia, num quadro marcado pela reflexividade do social e pela fragmentação dos sujeitos, o reconhecimento estará sempre em movimento, sempre haverá novos e renovados modos de avaliar justiças e injustiças e de tirar conseqüências políticas para as lutas por reconhecimento. Afinal, como os sujeitos sociais que lutam por reconhecimento entendem as injustiças, como suas causas são processadas pelo direito, e o como eles avaliam este processamento, serão sempre matéria renovada para a pesquisa.

\section{Referências}

BOLTANSKI, L. L'Amour et la justice comme compétences. Trois essais de sociololgie de l'action. Paris: Éditions Métailié, 1990.

BUTLER, J. Conclusiones dinámicas. In: BUTLER, J.; LACLAU, E.; ZIZEK, S. Contingencia, hegemonía, universalidad. Diálogos contemporáneos en la izquierda. Buenos Aires: Fondo de Cultura Argentina, 2000, p. 263-280.
BRASIL. Presidência da República. Lei n. 11.340, de 7 de agosto de 2006, Lei Maria da Penha. Disponível em: <http:/ /www.planalto.gov.br/ccivil/_Ato2004-2006/2006/Lei/ L11340.htm>. Acesso em: 15 maio 2007.

Presidência da República. Lei n. 9.099, de 26 de setembro de 1995. Dispõe sobre os Juizados Especiais Cíveis e Criminais e dá outras providências. Disponível em: <http://www.planalto.gov.br/ccivil_03/Leis/ L9099.htm>. Acesso em: 20 fev.2008.

BUTLER, J. O parentesco é sempre tido como heterossexual. Cadernos Pagu, n. 21, p. 219-260, 2003.

CORRÊA, M. Morte em família. Representações jurídicas de papéis sexuais. Rio de Janeiro: Graal, 1983.

DAMANT, D.; BELANGER, J.; PAQUET, J. Analyse du processus d'empowerment dans des trajectoires de femmes victimes de violence conjugale à travers le système judiciaire. Criminologie, Université Laval, Québec, v. 33, n.1,p. 73-95, 2000.

DEBERT, G. G. Arenas de conflitos éticos nas Delegacias Especiais de Polícia. Primeira Versão, n. 114, nov. 2002, publicação IFCH/Unicamp.

DERRIDA, J. Força de lei. O fundamento místico da autoridade. São Paulo: Martins Fontes, 2007.

DIGNEFFE, F. ; PARENT, C. La Mediation face aux situations de violence contre les conjointes: quelques elementsa verser au debat. In: CARTUYVELS, Y. et al. (Edit.). Politique, police et justice au bord du futur. Montreal: L'Harmattan, 1998, p.153-169.

GREGORI, M. F. Cenas e queixas: um estudo sobre mulheres, relações violentas e prática feminista. Rio de Janeiro/São Paulo: Paz e Terra/Anpocs, 1993.

GROSSI, M. Novas/velhas violências contra a mulher no Brasil. Revista Estudos Feministas, n. especial, p. 473-483, 1995.

HONNETH, A. Lutas por reconhecimento. A gramática moral dos conflitos sociais. São Paulo: Editora 34, 2003.

MATTOS, P. O reconhecimento entre a justiça e a identidade. Lua Nova, n. 63, p.143-161, 2004.

MUNIZ, J. Os direitos dos outros e outros direitos: um estudo sobre a negociação de conflitos nas DEAMs/RJ. In: SOARES, L. E. et al. Violência e política no Rio de Janeiro. Rio de Janeiro: ISER; Relume Dumará, 1996. p. 125-64.

OLIVEIRA, M. B. Crime invisivel: a mudança de significados da violência de gênero no Juizado Especial 
Criminal. 2006. Dissertação (Mestrado em Antropologia) Unicamp, Campinas, 2006.

PARENT, C. Face à l'insoutenable de la violence contre les conjointes: les femmes como actrices sociales.In: DEBUYST, C.; DIGNEFFE, F.; KAMINSKI, D.; PARENT, C. Essais sur le tragique et la rationalité pénale. Bruxelles: Éditions De Boek Université, 2002, p. 83-103.

PEDROSO, J. Percurso(s) da(s) reforma(s) da administração da justiça - uma nova relação entre o judicial e o não judicial. Oficinas do Centro de Estudos Sociais, n. 171, p. 1-43, abr. 2002.

PEDROSO, J.; TRINCÃO, C.; DIAS, J. P. Percursos da informalização e da desjudiciarização. Por caminhos da reforma da administração da justiça (análise comparada). Observatório Permanente da Justiça Portuguesa, do Centro de Estudos Sociais, Universidade de Coimbra, Coimbra, 2001.

RIFIOTIS, T. Nos campos da violência: diferença e positividade. Antropologia em Primeira Mão, Programa de Pós-Graduação em Antropologia Social-UFSC, v.19, n.1, p.18, 1997.

A Mídia, o leitor-modelo e a denúncia da violência policial: o caso Favela Naval (Diadema). Revista São Paulo em Perspectiva, SEAD, n. 4, 1999.

. La stratégie judiciaire et les pratiques policières dans les Commissariats Spéciaux de Protection de Femmes au Brésil. In : SYMPOSIUM INTERNATIONAL DE VICTIMOLOGIE, 10. Montreal, 2000. Reprografado.

. As delegacias especiais de proteção à mulher no Brasil e a 'judicialização' dos conflitos conjugais. In: SEMINÁRIO INTERNACIONAL RED \& GEDIM/ UNESCO. Anais... Rio de Janeiro, 2003. (Publicado na revista Sociedade e Estado, UnB, v. 19, n.1, 2004).

Repensando as estratégias de reconhecimento social dos direitos humanos. In: VIVARTA, V. (Coord.). Mídia e direitos humanos. Brasília, ANDI, Secretaria Especial dos Direitos Humanos, Unesco, 2006a.

. Alice do outro lado do espelho: revisitando as matrizes das violências e dos conflitos sociais. Revista de Ciências Sociais, Universidade Federal do Ceará, v. 37, n. 2,p. 27-33, 2006b.

Derechos humanos y otros derechos: aporias sobre procesos de judicialización e institucionalización de movimientos sociales. In: ISLA, A. (Comp.). En los márgenes de la ley. Inseguridad y violencia en el Cono Sur. Buenos Aires, Barcelona, México: Paidós, 2007a, p. 229-250.
RIFIOTIS, T. Direitos humanos: sujeito de direitos e direitos dos sujeitos. In: SILVEIRA, M. R. G. et al. Educação em direitos humanos: fundamentos teórico-metodológicos. João Pessoa: Editora Universitária, 2007b, p. 231-244.

RIFIOTIS, T.; SANTOS, V. R. Programme de soutien psycho-logique dans le commissariat de protection de la femme de la ville de Florianópolis (Brésil). Bulletin de l'Association Québécoise Plaidoyer-Victimes, Montreal, v. 11, n. 4 p. 2-4, 2002.

;___ O atendimento psicológico, a judicialização de conflitos conjugais e as delegacias de proteção à mulher. In: REUNIÃO DE ANTROPOLOGIA DO MERCOSUL, 6. Anais... Montevidéu, 2005. 1 CD-ROM.

SCOTT, J. O enigma da igualdade. Revista de Estudos Feministas, v. 13, n. 1, p. 11-30, jan./abr. 2005.

SHERMAN, L. Policing Domestic Violence. Experiments and Dilemmas. New York: The Free Press, 1992.

SIMIÃO, D. As donas da palavra: gênero, justiça e a invenção da violência doméstica. 2005. Tese (Doutorado em Antropologia) - Universidade de Brasília (UnB), Brasília, 2005.

SOARES, B. M. Mulheres invisíveis. Violência conjugal e novas políticas de segurança. Rio de Janeiro: Civilização Brasileira, 1999.

WEBER, M. Économie et société 1. Paris: Plons, 1995a.

. Économie et société 2. Paris: Plons, 1995b.

WELZER-LANG, D. Entretient avec Daniel Welzer Lang. La Construction du masculin. Sciences Humaines, Presses Sorbonne Nouvelle, n. 146, Février 2004.

WELZER-LANG, D.; ROUX, F. Les hommes violents. Paris: Lierre \&Courdrier, 1991.

\section{Notas}

1 Trata-se de uma versão revisada e ampliada de um texto publicado em CD-ROM nos Anais da VII RAM (Reunião de Antropologia do Mercosul), realizada em Porto Alegre, em 2007.

2 Faz parte das expectativas desta apresentação sugerir uma ampliação do diálogo que possa produzir estudos comparados no Brasil e no âmbito dos países do Mercosul.

3 Acredito que seja possível e pertinente no campo da pesquisa sobre 'violência' distinguir três tipos de discursos: 1) discurso 
contra a violência, marcado pela indignação; 2) discurso sobrea violência, tendo como eixo principal areflexão analítica; 3) discurso da violência, ou seja, a dimensão expressiva dos eventos designados como violentos, a sua leitura como uma linguagem social(RIFIOTIS, 1997, 1999).

4 Evidentemente, não se trata de colocar os discursos denunciatórios e tais noções genericamente em suspeição, e tampouco questionar a sua legitimidade e importância social. O que se pretende é colocá-los em suspensão, produzir uma desconstrução positiva, ou, nos termos de Butler (2000), borrar momentaneamente conceitos, seguindo um compromisso com uma interrogação autoconsciente e radical.

5 Por desviar a proposta do ensaio e para a sua economia, estamos utilizando genericamente a expressão 'violência de gênero' como uma categoria mais ampla que engloba a expressão 'violência conjugal'.

6 A temática da judiciarização está sendo objeto de um novo trabalho, lembro aqui de passagem a descrição dada anteriormente: "Processo complexo que não se limita à'violência conjugal', a 'judiciarização' traduz duplo movimento: de um lado a ampliação do acesso ao sistema judiciário, e por outro, a desvalorização de outras formas de resolução de conflito" (RIFIOTIS, 2004,p. 114).

7 No caso da Lei Maria da Penha que entrou em vigor no Brasil em 2006 eà qual voltaremos mais adiante no texto, trata-se de uma criminalização primária porque há tipificação legal.

8 Apenas para que se tenha uma idéia do caráter internacional da questão, citamos dois exemplos contemporâneos à criação daDM: o famoso The Minneapolis Police Experiment(EUA) e a política em matéria de violência conjugal do Quebec (Canadá).

9 Encontramos uma referência importante da temática da 'reprivatização' nos trabalhos de Debert (2002, p. 8), especialmente quando se refere à'violência doméstica': "Essa nova categoria transforma concepções da criminologia, na medida em que vítimas e acusados passam a ser tratados como uma espécie de cidadãos falhos, porque são incapazes de exercer direitos civis plenamente conquistados. As causas envolvidas na produção dos crimes são vistas como de caráter moral ou resultados da incapacidade dos membros da família em assumir papéis que devem ser desempenhados em cada uma dessas etapas do ciclo da vida familiar. Por outro lado, a expressão 'violência doméstica' é indicadora de um processo que chamarei de reprivatização de questões políticas, por meio do qual o papel da família é renovado, que passa a ser um aliado fundamental das políticas sociais [...].”

10 É oportuno para o desenvolvimento do argumento proposto aqui a distinção entre justiça e direito, seja na perspectiva já apontada da distinção entre'fazer justiça' e 'entrar na justiça', mencionada anteriormente, ou naquela mais conceitual proposta por Derrida (2007).

11 Sem pretender demodo algum afirmar ou confirmar qualquer 'tradição' ou 'costume', acompanhamos Weber apenas no sentido de destacar um fundamento social, segundo o qual poderíamos afirmar que a judiciarização implicaria no declínio de outros modos de regulação social e não constitui de per si uma modalidade de auto-regulação.

12 A relação entre o jurídico e o reconhecimento pelo Estado, como no caso do 'casamento gay' analisadopor Butler(2003, p. 226), parece que sempre implica numa 'dádiva ambivalente' e a criação de 'zonas de ilegitimidade', ou seja, implica na aceitação dos termos de legitimação oferecidos e dependentes do léxico dessa legitimação.

13 Esta questão foi discutida de modo detalhado num outro trabalho publicado anteriormente (RIFIOTIS, 2004).

14 Estamos trabalhando nesta perspectiva comparada com Sonia Gauthier, professora da Universidade de Montreal e pesquisadora do CRIVIFF (Centre de recherche interdisciplinaire sur la violence familiale et la violence faite aux femmes).

15 Axel Honneth, Nancy Fraser e Charles Taylor são os principais autores que têm trabalhado a questão do reconhecimento como central para a teoria social contemporânea. No presente ensaio, é adotada a perspectiva de Honneth, embora façamos referência ao trabalho de Fraser, através da análise de Mattos (2004). Nos limites do presente texto, tal opção justifica-se pela pertinência e necessidade de uma abordagem que permitisse especificar formas de reconhecimento como se encontra em Honneth. De fato, é fundamental para a discussão no campo do presente ensaio, tratar a questão do reconhecimento na pluralidade de dimensões envolvidas, como quando estudamos a 'violência conjugal', por exemplo. Assim, ao optar pela abordagem de Honneth, considerei fundamentalmente que as três formas de reconhecimento que ele propõe e as respectivas esferas sociais: amor e amizade (relações primárias); direito (relações jurídicas); e solidariedade (comunidade de valores). $\mathrm{O}$ quadro 'Estrutura das relações sociais de reconhecimento', apresentado mais adiante no texto, organiza estes elementos na perspectiva do próprio autor.

$16 \mathrm{O}$ que abre um interessante debate com as teses de Nancy Fraser e Axel Honneth, numa perspectiva comparada que já foi explorada por Mattos (2004).

17 Não se trata aqui de discutir um lugar para a'violência de gênero', por exemplo, e produzir um encaixe mecânico na teoria do reconhecimento, mas pensar o seu rendimento analítico para o nosso campo de reflexão. 
18 Especificamente sobre a constituição dos sujeitos de direitos e os direitos dos sujeitos, remeto o leitor a outro trabalho publicado recentemente e que aborda esta matéria (RIFIOTIS, 2007b).

\section{Theophilos Rifiotis}

Pós-doutor em Antropologia e Criminologia pela Université de Montréal (Canadá)

Doutor em Sociologia pela Universidade de São Paulo (USP)

Professor do Departamento de Antropologia do Centro de Filosofia e Ciências Humanas (CFH-UFSC)

Coordenador do Laboratório de Estudos das Violências (LEVIS)

Universidade Federal de Santa Catarina (UFSC)

Departamento de Antropologia (CFH)

Campus Universitário Reitor João David Ferreira

Lima

Trindade - Florianópolis - Santa Catarina

CEP: 88010-970 